\title{
Kajian Kejadian Berat Badan Lahir Rendah di Indonesia: Analisis Data Survei Demografi dan Kesehatan Indonesia Tahun 2017
}

\author{
The Study on Low Birth Weight in Indonesia: Analysis on the 2017 Indonesia \\ Demographic and Health Survey
}

Rimawati Aulia Insani Sadarang

Program Studi Kesehatan Masyarakat, Universitas Islam Negeri Alauddin Makassar, Makassar

\begin{abstract}
Abstrak
Kondisi Berat Badan Lahir Rendah (BBLR) berkontribusi tidak hanya pada angka kematian bayi tetapi juga pada masalah kesehatan lainnya. Penelitian ini bertujuan untuk mengetahui prevalensi BBLR dan mengidentfikasi perbedaan rata-rata BBLR di Indoensia berdasarkan usia ibu, tingkat pendidikan ibu, jenis tempat tinggal, lokasi tempat tinggal, indeks kesejahteraan, kunjungan antenatal care (ANC), dan konsumsi tablet Fe selama kehamilan. Penelitian ini menggunakan data survei Demografi dan Kesehatan Indonesia tahun 2017 dengan rancangan cross sectional study. Analisis data dilakukan terhadap wanita usia subur yang pernah melahirkan dan memiliki catatan berat badan lahir bayi pada Kartu Menuju Sehat (KMS)/ buku Kesehatan Ibu dan Anak (KIA) secara deskriptif dan analitik. Uji beda menggunakan one way anova, kruskall wallis, dan unpaired ttest dengan p-value 0,05 sebagai cut off point. Prevalensi BBLR mencapai angka $6,1 \%$. Rata-rata berat badan lahir terendah teridentifikasi dialami oleh ibu yang berusia 15-19 tahun (1.944,0 gram), tidak pernah menamatkan minimal satu jenjang pendidikan (1.925,0 gram), tidak pernah melakukan kunjungan ANC (1.900,0 gram), dan tidak pernah mengonsumsi tablet Fe selama kehamilan (1.750,0 gram). Berdasarkan lokasi dan indeks kesejahteraan, Pulau Jawa (34,5\%), wilayah perkotaan $(51,5 \%)$ dan keluarga dengan indeks kesejahteraan paling rendah $(29,4 \%)$ merupakan kontributor utama terhadap angka BBLR di Indonesia. Perbedaan rata-rata BBLR hanya signifikan secara statistik pada variabel tingkat pendidikan $(p=0,0279)$. Edukasi kepada ibu hamil terkait BBLR sangat dibutuhkan agar ibu hamil mengatahui faktor risiko BBLR yang dimiliki dan dapat melakukan pencegahan secara mandiri.
\end{abstract}

Kata Kunci: Antenatal Care, Berat Badan Lahir Rendah, Faktor Risiko.

\begin{abstract}
Low Birth Weight (LBW) was contributed not only to the infant mortality rate but also to other health problems. This research aims were to identify the prevalence of LBW and the mean comparison of LBW in Indonesia based on maternal age, education level, type of residence, location of living, wealth index, antenatal care (ANC) visit, and consumption of Fe supplements during pregnancy. This study used data from the 2017 Indonesia Demographic and Health Survey with cross sectional study design. Data analysis was carried out on women of childbearing age who had given birth and had records of baby's birth weight on the Card towards Healthy (KMS)/ Maternal and Child Health (MCH) book descriptively and analytically. The comparison test used one way ANOVA, Kruskal Wallis, and unpaired ttest with a pvalue of 0.05 as cut off point. The prevalence of LBW was $6.1 \%$. The lowest average birth weight was identified as experienced by mothers aged 15-19 years (1,944.0 grams), never completed at least one level of education (1,925.0 grams), never had ANC visits (1,900.0 grams), and never took Fe tablets during pregnancy (1,750.0 grams). Based on location and wealth index, Java Island (34.5\%), urban areas (51.5\%) and families with the lowest wealth index $(29.4 \%)$ were the main contributors to the LBW rate in Indonesia. There was a significant difference in the mean of LBW among the mother's education levels $(\mathrm{p}=0.0279)$. Education for pregnant women regarding LBW was needed. Thus they knew their LBW risk factors and could do prevention independently.
\end{abstract}

Keywords: Antenatal Care, Low Birth Weight, Risk Factor

Korespondensi : Rimawati Aulia Insani Sadarang

Email : rimawati.aulia@uin.alauddin.ac.id 


\section{PENDAHULUAN}

Bayi dengan Berat Badan Lahir Rendah (BBLR), yakni kurang dari 2.500 gram, merupakan masalah kesehatan yang turut berkontribusi terhadap angka kematian bayi. Setiap tahun, dari 20 juta kelahiran di seluruh dunia diestimasikan terdapat 15-20\% bayi terlahir dengan BBLR (1). Bayi tersebut tidak hanya berisiko mengalami kematian di bulan awal kehidupan, tetapi juga berisiko untuk mengalami masalah kesehatan lainnya, seperti masalah pertumbuhan, IQ rendah, dan masalah kesehatan kronis saat dewasa (2). Penurunan angka BBLR telah menjadi fokus dunia yang tertuang dalam Sustainable Development Goals (SDGs). Pada tahun 2025 ditargetkan telah tercapai penurunan angka BBLR hingga 30\%. Hal ini berarti setiap tahun pada periode 2012 - 2025 setidaknya terjadi penurunan relatif angka BBLR sebesar 3\% atau terjadi penurunan angka BBLR dari 20 juta menjadi 14 juta (1).

Pada tahun 2019 penyebab kematian neonatal terbanyak di Indonesia adalah kondisi BBLR. Data Direktorat Gizi Masyarakat tahun 2019 menunjukkan terdapat sekitar 3,4\% bayi dengan BBLR dilaporkan oleh 25 dari 34 provinsi di Indonesia, sementara hasil pelaksanaan Riskesdas tahun 2018 menunjukkan 6,2\% dari 56\% balita yang memiliki catatan berat lahir teridentifikasi terlahir dengan kondisi BBLR (3).

Penelitian ini bertujuan untuk mengetauhi prevalensi kejadian BBLR di Indonesia dan mengidentifikasi ada tidaknya perbedaan rata-rata berat badan lahir rendah berdasarkan usia ibu, tingkat pendidikan ibu, jenis tempat tinggal, lokasi tempat tinggal, indeks kesejahteraan, kunjungan antenatal care (ANC), dan konsumsi tablet Fe selama kehamilan.

\section{METODE}

Penelitian ini menggunakan data Survei Demografi dan Kesehatan Indonesia tahun 2017 dengan rancangan cross sectional. Populasi penelitian adalah seluruh wanita usia subur di Indonesia sedangkan sampel penelitian adalah wanita usia subur yang pernah melahirkan dan memiliki catatan berat badan lahir bayi pada Kartu Menuju Sehat (KMS)/ buku Kesehatan Ibu dan Anak (KIA). Analisis data diawali dengan proses cleaning dan coding data sesuai kebutuhan penelitian. Data selanjutnya dianalisis secara deskriptif untuk memperoleh gambaran karakteristik dan distribusi variabel penelitian. Analisis data secara analitik dilakukan untuk mengidentifikasi ada tidaknya perbedaan rata-rata berat badan lahir rendah antar kategori variabel penelitian. Proses identifikasi ini menggunakan uji one way anova, kruskall wallis, dan unpaired ttest. Signifikansi hasil analisis ditentukan berdasarkan nilai $p$ value 0,05 sebagai cut off point.

\section{HASIL PENELITIAN}

Terdapat $293(6,1 \%)$ kelahiran hidup dengan berat badan di bawah 2,500 gram di Indonesia. Kejadian BBLR terdata dominan dialami oleh ibu berusia 25-29 tahun (26,6\%), namun rata-rata berat badan lahir terendah, yakni 1.944,0 gram teridentifikasi dialami oleh ibu yang berusia 15-19 tahun. Berdasarkan tingkat pendidikan, ibu yang tidak pernah menamatkan minimal satu jenjang pendidikan, melahirkan bayi dengan rata-rata berat badan lahir 1.925,0 gram. Kejadian BBLR teridetifikasi terjadi di seluruh wilayah Indonesia. Pulau Jawa (34,5\%) dan wilayah perkotaan $(51,5 \%)$ merupakan kontributor utama terhadap angka BBLR di Indonesia. Sebanyak $(29,4 \%)$ bayi dengan BBLR berasal dari keluarga dengan indeks kesejahteraan berada pada kategori paling rendah (sangat miskin). 
Riwayat perawatan selama kehamilan ibu menunjukkan kontribusi terhadap angka BBLR. Teridentifikasi bayi dengan rata-rata berat badan dibawah 2,000 gram, yakni 1.900,0 gram dilahirkan oleh ibu yang tidak pernah melakukan kunjungan ANC sementara bayi dengan berat lahir yang hanya mencapai 1.750,0 gram dilahirkan oleh ibu yang tidak pernah mengonsumsi tablet Fe selama kehamilan.

Tabel 1. Distribusi Frekuensi dan Perbandingan Berat Badan Lahir Rendah di Indonesia

\begin{tabular}{|c|c|c|c|c|}
\hline \multirow{2}{*}{ Variabel } & \multicolumn{3}{|c|}{ Berat Badan Lahir Rendah } & \multirow[b]{2}{*}{ P value } \\
\hline & Jumlah (\%) & Rata-Rata (g) & Standar Deviasi & \\
\hline \multicolumn{5}{|l|}{ Usia ibu (tahun) } \\
\hline $15-19$ & $10(3,4)$ & $1.944,0$ & 438,4 & $0,212^{*}$ \\
\hline $20-24$ & $55(18,8)$ & $2.155,4$ & 260,4 & \\
\hline $25-29$ & $78(26,6)$ & $2.125,4$ & 318,3 & \\
\hline $30-34$ & $69(23,5)$ & $2.123,8$ & 321,0 & \\
\hline $35-39$ & $54(18,4)$ & $2.059,2$ & 368,8 & \\
\hline $40-44$ & $21(7,2)$ & $2.050,0$ & 335,4 & \\
\hline $45-49$ & $6(2,1)$ & $2.166,6$ & 314,1 & \\
\hline \multicolumn{5}{|l|}{ Tingkat pendidikan } \\
\hline Tidak ada & $4(1,4)$ & $1.925,0$ & 298,6 & $0,0279 * *$ \\
\hline Dasar & $88(30.0)$ & $2.060,5$ & 326,9 & \\
\hline Menengah & $159(54.3)$ & $2.145,4$ & 300,4 & \\
\hline Tinggi & $42(14.3)$ & $2.081,3$ & 394,9 & \\
\hline \multicolumn{5}{|l|}{ Lokasi tempat tinggal } \\
\hline Sumatera & $56(19,1)$ & $2.117,3$ & 297,9 & $0,066^{*}$ \\
\hline Jawa & $101(34,5)$ & $2.096,4$ & 360,4 & \\
\hline Bali & $6(2,1)$ & $2.133,3$ & 320,4 & \\
\hline Nusa Tenggara & $30(10,2)$ & $2.139,3$ & 239,4 & \\
\hline Kalimantan & $37(12,6)$ & $2.128,4$ & 318,2 & \\
\hline Sulawesi & $46(15,7)$ & $2.085,5$ & 335,0 & \\
\hline Maluku & $9(3,1)$ & $2.011,1$ & 451,2 & \\
\hline Papua & $8(2,7)$ & $2.187,5$ & 172,7 & \\
\hline \multicolumn{5}{|l|}{ Jenis tempat tinggal } \\
\hline Perkotaan & $151(51,5)$ & $2.119,6$ & 344,2 & $0,2031 * * *$ \\
\hline Pedesaan & $142(48,5)$ & $2.095,1$ & 303,5 & \\
\hline \multicolumn{5}{|l|}{ Indeks kesejahteraan } \\
\hline Sangat miskin & $86(29,4)$ & $2.089,7$ & 316,7 & $0,3452 * *$ \\
\hline Miskin & $58(19,8)$ & $2.109,2$ & 319,6 & \\
\hline Menengah & $60(20,5)$ & $2.175,6$ & 269,2 & \\
\hline Kaya & $51(17,4)$ & $2.101,1$ & 330,9 & \\
\hline Sangat kaya & $38(12,9)$ & $2.047,9$ & 411,5 & \\
\hline \multicolumn{5}{|l|}{ Kunjungan ANC } \\
\hline Tidak pernah & $2(0,7)$ & $1.900,0$ & 565,7 & $0,180^{*}$ \\
\hline$<4$ kali & $20(6,8)$ & $2.076,0$ & 238,2 & \\
\hline$\geq 4$ kali & $271(92,5)$ & $2.111,6$ & 329,4 & \\
\hline \multicolumn{5}{|l|}{ Konsumsi tablet Fe } \\
\hline Tidak pernah & $2(0,8)$ & $1.750,0$ & 777,8 & $0,7217 * *$ \\
\hline$<90$ hari & $135(52,1)$ & $2.122,6$ & 294,7 & \\
\hline$\geq 90$ hari & $122(47,1)$ & $2.104,6$ & 344,2 & \\
\hline
\end{tabular}


*oneway anova

**kruskal wallis

***mann whitney

Hasil pengujian beda rerata berat badan lahir antar ketegori variabel menunjukkan hanya variabel tingkat pendidikan yang menunjukkan perbedaan rerata berat badan lahir antar kategori yang signifikan secara statistik $(p<0,05)$.

\section{PEMBAHASAN}

Usia ibu memiliki peran terhadap peluang kejadian BBLR. Ibu yang berusia di bawah 20 tahun teridentifikasi melahirkan bayi dengan rata-rata berat badan terendah jika dibandingkan dengan ibu berusia di atas 20 tahun yang juga melahirkan bayi dengan berat badan $<2.500$ gram. Hasil penelitian ini sejalan dengan penelitian yang dilakukan di China, Pakistan dan Yordania (4-6). Tidak terdapat perbedaan rerata BBLR antar kelompok usia ibu yang signifikan secara statistik. Hal ini dapat diartikan bahwa risiko BBLR dapat dialami oleh ibu pada semua kelompok usia. Setiap penambahan atau pengurangan satu tahun usia ibu akan meningkatkan atau menurunkan 4,3 gram berat bayi yang dilahirkan (5). Namun, penelitian sebelumnya secara spesifik menunjukkan adanya peningkatan risiko BBLR pada kelompok usia ibu tertentu yang digambarkan dengan kurva U $(4,6)$. Risiko BBLR teridentifikasi lebih tinggi dialami oleh ibu berusia $<20$ tahun dan $>34$ tahun.

Peningkatan risiko BBLR yang dimiliki oleh ibu pada kelompok usia tertentu berkaitan dengan kondisi biologis sistem reproduksi. Pada kelompok usia ibu $<20$ tahun, kematangan sistem reproduksi dinilai belum/ kurang memadai untuk menerima kehamilan sementara pada kelompok usia ibu >34 tahun, penurunan kondisi kesehatan ibu dan kualitas sel telur dapat meningkatkan kerentanan ibu terhadap preeklamsia dan hipertensi terkait kehamilan yang dapat mempengaruhi proses tumbuh kembang janin sehingga komplikasi atau kelahiran prematur yang mengakibatkan BBLR $(4,7,8)$.

Pendidikan memegang peranan penting pada pembangunan sosial dan ekonomi yang akan berdampak pada status kesehatan. Kurangnya pendidikan akan berimplikasi pada kurangnya kemampuan untuk menemukan, memahami dan menggunakan informasi kesehatan yang tersedia. Tingkat pendidikan, baik secara langsung maupun tidak langsung, dapat mempengaruhi berat badan lahir bayi melalui pengetahuan yang diperoleh terkait perawatan dan nutrisi selama kehamilan (6).

Perbedaan signifikan rerata BBLR antar kelompok tingkat pendidikan ibu yang teridentifikasi pada penelitian ini mendukung penelitian sebelumnya yang menunjukkan adanya hubungan antara tingkat pendidikan ibu dengan kejadian BBLR $(9,10)$. Penelitian yang dilakukan di Brazil menunjukkan penurunan signifikan rata-rata BBLR di antara bayi yang terlahir dari ibu dengan tingkat pendidikan yang lebih tinggi (11). Peningkatan satu tahun tingkat pendidikan ibu akan berimplikasi pada peningkatan 75 gram berat badan lahir bayi (5). Tidak adanya perbedaan rerata berat badan lahir bayi berdasarkan lokasi dan jenis tempat tinggal ibu menunjukkan bahwa BBLR masih menjadi masalah di seluruh wilayah Indonesia dan membutuhkan penanganan yang komprehensif. Jika ditinjau dari jenis tempat tinggal, angka BBLR di wilayah perkotaan seharusnya dapat jauh lebih rendah jika dibandingkan 
dengan wilayah pedesaan mengingat fasilitas kesehatan, sarana dan prasarana yang mendukung pemanfaatan fasilitas kesehatan telah tersedia.

Salah satu faktor yang dapat mempengaruhi pemanfaatan fasilitas kesehatan yang tersedia adalah indeks kesejahteraan. Pada penelitian ini tidak teridentifikasi adanya perbedaan rerata berat badan lahir bayi yang signifikan secara statistik antar kelompok indeks kesejahteraan, namun proporsi BBLR teridentifikasi lebih tinggi pada kelompok indeks kesejateraan terendah/ sangat miskin. Hasil penelitian ini sejalan dengan hasil penelitian di Bangladesh, Pakistan, India, Burundi dan beberapa negara berkembang lainnya $(5,10,12-14)$. Indeks kesejahteraan keluarga menunjukkan hubungan yang linear terhadap berat badan bayi yang dilahirkan dalam keluarga tersebut. Hal ini berarti semakin tinggi indeks kesejahteraan keluarga maka semakin tinggi pula peluang bayi yang dilahirkan akan memiliki berat badan normal/ ideal. Ibu hamil dengan indeks kesejahteraan baik/ menengah ke atas memiliki kemampuan untuk mengakses fasilitas, sarana dan prasarana terkait kesehatan yang lebih baik, seperti konsumsi makanan bernutrisi selama kehamilan untuk mendukung proses tumbuh kembang janin dan menghindarkan diri dari terjadinya komplikasi selama kehamilan, dibandingkan ibu hamil dengan indeks kesejahteraan menengah ke bawah (5).

Pemanfaatan pelayanan selama kehamilan atau antenatal care (ANC) memiliki manfaat untuk menghindarkan ibu hamil terhadap komplikasi selama kehamilan yang dapat mempengaruhi berat badan lahir bayi. Ibu hamil direkomendasikan memanfaatkan pelayanan ANC setidaknya empat kali selama masa kehamilan (15). Beberapa penelitian sebelumnya telah menunjukkan ibu hamil yang memanfaatkan pelayanan ANC teridentifikasi memiliki risiko lebih kecil yang signifikan secara statistik untuk melahirkan bayi BBLR $(10,16,17)$. Sejalan dengan hasil penelitian tersebut, pada penelitian ini, rerata berat badan lahir pada kelompok ibu yang tidak pernah melakukan kunjungan ANC teridentifikasi lebih rendah dibandingkan kelompok ibu yang melakukan kunjungan ANC.

Berat badan lahir bayi dapat diestimasikan melalui kenaikan berat badan ibu hamil yang dimonitoring secara berkala melalui kunjungan ANC. Sekitar 50\% kenaikan volume plasma sebanding dengan berat badan lahir bayi yang terjadi terutama pada periode trimester ketiga (16). Penelitian yang dilakukan di Nigeria dan Uni Emirat Arab secara spesifik menunjukkan pengaruh inisiasi kunjungan ANC terhadap berat badan lahir bayi. Ibu hamil yang melakukan kunjungan ANC pertama kali saat usia kehamilan 13 minggu/trimester kedua berpotensi untuk melahirkan bayi dengan BBLR (18). Sekitar 26,7\% bayi dengan BBLR dilahirkan oleh ibu hamil yang baru melakukan kunjungan ANC pada trimester ketiga (usia kehamilan 21-36 minggu), dan masing-masing $20 \%$ dan $9 \%$ dilahirkan oleh ibu yang melakukan kunjungan ANC pertama kali pada trimester kedua dan pertama (19).

Nutrisi selama kehamilan sangat penting untuk mencegah BBLR. Konsumsi tablet Fe menjadi penting untuk memenuhi kebutuhan zat besi selama kehamilan dan mencegah terjadinya anemia. Zat besi sangat penting dalam perkembangan berat janin sebab transformasi mineral dan zat makanan lain dari ibu kepada janin dipengaruhi oleh ketersediaan hemoglobin dalam sel darah merah ibu (20). Ibu hamil yang tidak mengonsumsi tablet Fe selama kehamilan teridentifikasi melahirkan bayi dengan berat badan lahir terendah jika dibandingkan dengan ibu hamil yang mengonsumsi tablet Fe yang juga melahirkan bayi dengan BBLR. Hasil penelitian ini sejalan dengan penelitian sebelumnya yang menunjukkan risiko ibu melahirkan bayi dengan BBLR lebih rendah ketika ibu mengonsumsi tablet Fe selama kehamilan (20-23). 


\section{KESIMPULAN DAN SARAN}

Prevalensi kejadian BBLR di Indonesia mencapai angka 6,1\% dan tidak terdapat perbedaan rata-rata berat badan lahir rendah yang signifikan secara statistik berdasarkan usia ibu, jenis tempat tinggal, lokasi tempat tinggal, indeks kesejahteraan, kunjungan ANC, dan konsumsi tablet Fe selama kehamilan. Perbedaan rata-rata berat badan lahir rendah yang signifikan secara statistik hanya teridentifikasi pada variabel tingkat pendidikan. Kejadian BBLR adalah masalah kesehatan yang kompleks dan membutuhkan pendekatan multisektor dalam upaya pencegahan dan penanganan. Edukasi kepada ibu hamil terkait BBLR sangat dibutuhkan agar ibu hamil mengatahui faktor risiko BBLR yang dimiliki dan dapat melakukan pencegahan secara mandiri.

\section{DAFTAR PUSTAKA}

1. WHO. Global Nutrition Targets 2025: Low Birth Weight Policy Brief [Internet]. Geneva; 2014 [cited 2021 Aug 3]. Available from: https://apps.who.int/iris/bitstream/handle/10665/149020/WHO_NMH_NHD_14.5_eng .pdf?ua $=1$

2. Unicef. Low birthweight [Internet]. unicef data. 2019 [cited 2021 Aug 3]. Available from: https://data.unicef.org/topic/nutrition/low-birthweight/

3. Kementerian Kesehatan RI. Profil Kesehatan Indonesia Tahun 2019 [Internet]. Jakarta; 2020 Jun [cited 2021 Aug 3]. Available from: https://pusdatin.kemkes.go.id/resources/download/pusdatin/profil-kesehatanindonesia/Profil-Kesehatan-indonesia-2019.pdf

4. Wang S, Yang L, Shang L, Yang W, Qi C, Huang L, et al. Changing trends of birth weight with maternal age: a cross-sectional study in Xi'an city of Northwestern China. BMC Pregnancy Childbirth 2020201 [Internet]. 2020 Nov 30 [cited 2021 Aug 3];20(1):1-8. Available from: https://bmcpregnancychildbirth.biomedcentral.com/articles/10.1186/s12884-02003445-2

5. Ghouse G, Zaid M. Determinants of Low Birth Weight a Cross Sectional Study: In Case of Pakistan. Munich Pers RePEc Arch [Internet]. 2018;30 Maret(70660):1-26. Available from: https://mpra.ub.uni-muenchen.de/70660/

6. Islam MM, Ababneh F, Akter T, Khan HR. Prevalence and risk factors for low birth weight in Jordan and its association with under-five mortality: a population-based analysis. East Mediterr Heal J [Internet]. 2020 [cited 2021 Aug 3];26(10):1273-84. Available from: https://doi.org/10.26719/emhj.20.096

7. Delfita N, Desmiwarti D, Agus M. Relationship Of Mother Factors With Low Birth Weight (LBW) Infants Which Are Treated In DR.M. Djamil Central Public Hospital Padang. J Midwifery [Internet]. 2017 Dec 21 [cited 2021 Aug 3];2(2):66-73. Available from: http://jom.fk.unand.ac.id/index.php/jom/article/view/18

8. Indriyani R, Hannan M, Hidayat S. Risk Factors for Low Birth Weight in Puskesmas Gading. Eur J Mol Clin Med [Internet]. 2020 [cited 2021 Aug 3];07(07):21-7. Available from: https://ejmcm.com/article_1706_7709c10028e7d0e1f58dd9fa478c5c81.pdf

9. Ratnam S. Maternal Risk Factors Associated with Term Low Birth Weight Infants: A Case-Control Study. Ann Community Med Public Heal [Internet]. 2021 Jan 8 [cited 2021 Aug 3];1(1):1-9. Available from: http://www.remedypublications.com/openaccess/maternal-risk-factors-associated-with-term-low-birth-weight-infants-6596.pdf

10. Khan JR, Islam MM, Awan N, Muurlink O. Analysis of low birth weight and its co- 
variants in Bangladesh based on a sub-sample from nationally representative survey. BMC Pediatr [Internet]. 2018 [cited 2021 Aug 4];18(100):1-9. Available from: https://bmcpediatr.biomedcentral.com/track/pdf/10.1186/s12887-018-1068-0.pdf

11. Silvestrin S, naomi Hirakata V, Homrich da Silva clécio, Zubaran Goldani M. Inequalities in birth weight and maternal education: a time-series study from 1996 to 2013 in Brazil. Sci Rep [Internet]. 2020 [cited 2021 Aug 3];10(8707):1-8. Available from: https://doi.org/10.1038/s41598-020-65445-8

12. Banerjee A, Singh AK, Chaurasia H. An exploratory spatial analysis of low birth weight and its determinants in India. Clin Epidemiol Glob Heal [Internet]. 2020 Sep 1 [cited 2021 Aug 4];8(3):702-11. Available from: http://cegh.net/article/S2213398420300142/fulltext

13. Misago N, Habonimana D, Ouedraogo L, Bitangumutwenzi P, Orcid NM. Progressing Aspects in Pediatrics and Neonatology Prevalence and Determinants of Low Birth Weight in Burundi: An Investigation from The National Demographic and Health Survey. Progress Asp Pediatr Neonatol [Internet]. 2021 Mar 2 [cited 2021 Aug 4];3(2):232-8. Available from: https://lupinepublishers.com/pediatrics-neonataljournal/pdf/PAPN.MS.ID.000157.pdf

14. Mahumud RA, Sultana M, Sarker AR. Distribution and Determinants of Low Birth Weight in Developing Countries. J Prev Med Public Heal [Internet]. 2017 Jan 1 [cited 2021 Aug 4];50(1):28. Available from: /pmc/articles/PMC5327679/

15. WHO. WHO recomandetion on antenatal care for positive pregnancy experiance. Vol. 1, World Health Organization. Geneva: World Health Organization; 2016. 1-198 p.

16. Djokosujono K, Putra WKY, Utari DM, Fajarini IA. Prediction of Low Birth Weight Based on Maternal Third Trimester Weight Among Mothers At a Maternal Clinic in Jakarta, Indonesia. Media Gizi Indones. 2021;16(2):106.

17. Zhou H, Wang A, Huang X, Guo S, Yang Y, Martin K, et al. Quality antenatal care protects against low birth weight in 42 poor counties of Western China. PLoS One [Internet]. 2019 Jan 1 [cited 2021 Aug 4];14(1):e0210393. Available from: https://journals.plos.org/plosone/article?id=10.1371/journal.pone.0210393

18. Ali N, Elbarazi I, Alabboud S, Al-Maskari F, Loney T, Ahmed LA. Antenatal Care Initiation Among Pregnant Women in the United Arab Emirates: The Mutaba'ah Study. Front Public Heal [Internet]. 2020 Jun 11 [cited 2021 Aug 4];8(211):1-7. Available from: https://www.frontiersin.org/articles/10.3389/fpubh.2020.00211/full

19. Isiugo-Abanihe UC, Oke OA. Maternal and environmental factors influencing infant birth weight in Ibadan, Nigeria. African Popul Stud [Internet]. 2011 Nov [cited 2021 Aug 4];25(2):250-66. Available from: http://www.bioline.org.br/pdf?ep11026

20. Zulliati, Hestiyana N. Pengaruh Zat Besi (Tablet Fe) Terhadap Berat Badan Lahir Pada Ibu Bersalin Normal. Din Kesehat J Kebidanan Dan Keperawatan. 2020;10(1):470-5.

21. Yang J, Cheng Y, Pei L, Jiang Y, Lei F, Zeng L, et al. Maternal iron intake during pregnancy and birth outcomes: a cross-sectional study in Northwest China. Br J Nutr [Internet]. 2017 Mar 28 [cited 2021 Aug 5];117(6):862-71. Available from: https://www.cambridge.org/core/journals/british-journal-of-nutrition/article/maternaliron-intake-during-pregnancy-and-birth-outcomes-a-crosssectional-study-in-northwestchina/4C443EAF21FE8CDDFC9E7C6138B5970C

22. Simarmata VPA, Sirait BI. The Relationship between History of Providing Fe Supplementation to Mothers during Pregnancy with Low Birth Weight Rate in Toddlers Age 0-59 Months in Mekarbakti Village, Sumedang Regency, West Java in 2020. Solid State Technol [Internet]. 2020 [cited 2021 Aug 4];63(1):1355-67. Available from: http://repository.uki.ac.id/2656/1/TheRelationshipbetweenHistory.pdf

23. Sudarmaningsih DP, Hikmah F, Widada NS, Ariningpraja RT. Risiko Anemia dan 
BBLR setelah Pemberian Fe pada Ibu Hamil di Puskesmas Kecamatan Kebayoran Baru. J Ilmu Keperawatan J Nurs Sci. 2021;9(1):109-15. 